\title{
Faktor Lingkungan Sebagai Pemoderasi Pengaruh Motivasi Berwirausaha Terhadap Minat Berwirausaha
}

\author{
Farah Putri Wenang Lusianingrum ${ }^{1}$, Esti Nur Wakhidah ${ }^{2}$, Frida \\ Fatmayati $^{3}$ \\ Universitas Sultan Ageng Tirtayasa ${ }^{1}$, Sekolah Tinggi Teknologi Kedirgantaraan ${ }^{2,3}$ \\ email korespondensi: farahputriwenang@untirta.ac.id
}

\begin{abstract}
Abstrak: Yogyakarta International Airport (YIA) merupakan bandar udara baru yang resmi beroperasi mulai 29 April 2019. Adanya YIA menciptakan peluang usaha yang dapat dimanfaatkan oleh masyaratat sekitar. Namun, peluang usaha ini kebanyakan dimanfaatkan oleh masyarakat maupun investor dari luar daerah. Perlu adanya kajian mengenai minat berwirausaha pada masyarakat sekitar YIA. Studi ini mempunyai tujuan untuk menguji dampak motivasi berwirausaha terhadap minat berwirausaha. Selain itu, adanya perbedaan hasil uji pengaruh langsung motivasi pada minat berwirausaha maka diusulkan faktor lingkungan untuk diuji sebagai variabel pemoderasi. Studi ini memilih menggunakan pendekatan kuantitatif. Populasi dalam studi ini masuk pada golongan studi infinit. Penentuan responden studi ini memakai non-probability sampling yaitu purposive sampling dan diperoleh responden sebanyak 100 orang. Data studi ini yaitu data primer karena data langsung diambil dari responden dengan memakai instrumen berupa kuesioner. Hasil pengujian studi ini memperlihatkan bahwa motivasi berwirausaha berpengaruh positif terhadap minat berwirausaha. Selanjutnya, pengaruh motivasi berwirausaha terhadap minat berwirausaha dimoderasi oleh lingkungan juga terdukung.

Kata kunci: Minat Berwirausaha, Motivasi Berwirausaha, Lingkungan, Yogyakarta International Airport (YIA).
\end{abstract}

Visi mengenai pembangunan ekonomi secara nasional Indonesia yang tertulis dalam Rencana Pembangunan Jangka Panjang (RPJP) yaitu "Terwujudnya perekonomian yang maju, mandiri, dan mampu secara nyata memperluas peningkatan kesejahteraan masyarakat" (Bappenas, 2005). Guna mewujudkan visi untuk menjadi negara maju suatu negara minimal harus memiliki sebanyak dua persen penduduknya sebagai wirausaha (Sektiyaningsih, Hardianawati, dan Aisyah, 2020). Namun, angka rasio dari jumlah wirausaha dengan populasi di Indonesia masih rendah dibandingkan dengan negara anggota ASEAN lainnya seperti Singapura, Malaysia, dan Thailand (Nurmayanti, 2020). Pemerintah terus berusaha untuk mendorong peningkatan jumlah wirausaha, sebab rasio tersebut menjadi indikator dari kemajuan pembangunan ekonomi suatu negara (Hendrawan dan Sirine, 2017).

Usaha peningkatan jumlah wirausaha dilakukan dengan melaksanakan pembangunan infrastruktur strategis guna mendukung kegiatan ekonomi masyarakat. Salah satunya yaitu pembangunan Bandar Udara Yogyakarta Internatioan Airport atau dikenal dengan YIA di Kecamatan Temon, Kabupaten Kulon Progo. YIA resmi beroperasi mulai 29 April 2019. Adanya YIA menciptakan peluang usaha yang dapat dimanfaatkan oleh masyarakat sekitar dari desa-desa yang terdampak adanya pembangunan YIA tersebut. Namun, peluang usaha ini kebanyakan dimanfaatkan oleh masyarakat maupun investor dari luar 
daerah. Dengan demikian, perlu adanya kajian mengenai minat berwirausaha pada masyarakat sekitar YIA.

Minat berwirausaha masyarakat ini perlu dipelajari sebab untuk mengetahui faktor yang dapat mendorong individu menjadi wirausaha. Suratno, Kohar, Rusmiati, dan Kurniawan (2020) menyebutkan bahwa individu yang mempunyai minat berwirausaha dinilai akan lebih giat dan tekun dalam mencari serta memanfaatkan peluang usaha dengan memaksimalkan potensinya. Faktor psikologis individu seperti motivasi berwirausaha terbukti mampu memberikan dorongan yang kuat pada minat berwirausaha (Sektiyaningsih et al., 2020; Aqmala, Putra, dan Suseno, 2020).

Hendrawan dan Sirine (2017) menyebutkan bahwa motivasi berwirausaha dari dalam diri dapat menentukan minat dan usaha yang akan digunakan untuk mewujudkan minat tersebut. Dengan kata lain motivasi mampu untuk mengubah motif-motif dalam diri menjadi suatu perilaku nyata sebagai upaya mencukupi kebutuhan ataupun mewujudkan minatnya. Tidak mengherankan apabila motivasi berwirausaha ini dipercaya menjadi faktor yang kuat dalam memprediksi minat berwirausaha (Aqmala et al., 2020; Sektiyaningsih et al., 2020; dan Suratno et al., 2020).

Namun, studi yang dilaksanakan oleh Fadillah dan Thamrin (2019) serta Lubis (2018) menunjukkan hasil yang berbeda bahwa motivasi berwirausaha secara statistik tidak memberikan pengaruh terhadap minat berwirausaha. Perbedaan hasil studi ini menunjukkan bahwa perlu dilakukan studi kembali mengenai pengaruh motivasi berwirausaha terhadap minat berwirausaha. Selain itu, penelitian ini mengusulkan faktor lingkungan untuk dijadikan sebagai pemoderasi guna mengatasi kesenjangan hasil studi empiris.

Faktor lingkungan ini dijadikan sebagai variabel pemoderasi karena beberapa alasan. Pertama, lingkungan merupakan faktor eksternal terbukti mampu untuk meningkatkan minat berwirausaha (Aqmala et al., 2020). Kedua, Yusuf dan Sutanti (2020) mengemukakan bahwa faktor lingkungan terdiri dari lingkungan fisik dan psikologis yang mampu memperkuat pengaruh faktor psikologis terhadap minat berwirausaha. Terakhir, Nainggolan dan Harny (2020) menyatakan bahwa adanya perubahan pada kondisi lingkungan dengan ketidakpasatian memberikan pengaruh pada kondisi psikologis dan minat yang dimiliki individu. Dengan demikian, penelitian ini tidak hanya menguji pengaruh motivasi terhadap minat berwirausaha tetapi juga menguji pengeruh pemoderasi faktor lingkungan pada pengaruh motivasi terhada minat berwirausaha.

\section{METODE}

Pendekatan kuantitatif dipilih dalam studi ini karena dinilai menjadi pendekatan yang tepat untuk menjawab rumusan dan tujuan penelitian. Data yang digunakan dalam studi ini yaitu data primer yang diperoleh dari responden yang mengisi kuesioner. Kuesioner penelitian dibagikan secara 


\section{HASIL}

Data yang telah terkumpul selanjutnya akan dianalisis lebih lanjut menggunakan SEM PLS melalui dua tahapan. Tahap pertama ini akan dilakukan pengujian untuk melihat validitas dan reliabilitas dari item pernyataan yang digunakan untuk mengukur variabel motivasi berwirausaha, lingkungan, dan minat berwirausaha. Berikut ini hasil dari pengujian validitas konvergen dan reliabilitas dari ketiga variabel tersebut pada Tabel 2.

Tabel 2. Validitas Konvergen dan Reliabilitas

\begin{tabular}{|c|c|c|c|c|}
\hline Item Pernyataan & $\begin{array}{l}\text { Factor } \\
\text { Loading }\end{array}$ & $\begin{array}{c}\text { Cronbach's } \\
\text { Alpha }\end{array}$ & $\begin{array}{c}\text { Composite } \\
\text { Reliability }\end{array}$ & Keputusan \\
\hline \multicolumn{5}{|c|}{ Motivasi Berwirausaha } \\
\hline $\begin{array}{l}\text { 1. Tuntutan ekonomi } \\
\text { mendorong Anda } \\
\text { untuk } \\
\text { berwirausaha }\end{array}$ & 0,825 & 0,824 & 0,877 & $\begin{array}{l}\text { Valid dan } \\
\text { Reliabel }\end{array}$ \\
\hline $\begin{array}{l}\text { 2. Adanya } \\
\text { permintaan akan } \\
\text { produk/jasa }\end{array}$ & 0,816 & & & \\
\hline $\begin{array}{l}\text { disekitar Anda } \\
\text { yang memotivasi } \\
\text { untuk } \\
\text { berwirausaha }\end{array}$ & & & & \\
\hline 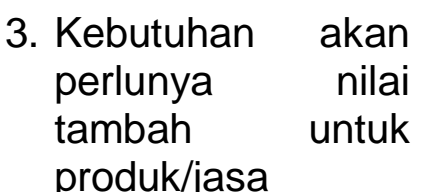 & 0,744 & & & \\
\hline $\begin{array}{l}\text { disekitar Anda } \\
\text { momotivasi untuk } \\
\text { berwirausaha }\end{array}$ & & & & \\
\hline $\begin{array}{l}\text { 4. Adanya sumber } \\
\text { daya yang } \\
\text { melimpah disekitar } \\
\text { Anda mendorong } \\
\text { untuk } \\
\text { berwirausaha }\end{array}$ & 0,793 & & & \\
\hline $\begin{array}{l}\text { 5. Banyaknya } \\
\text { pengangguran } \\
\text { dilingkungan } \\
\text { sekitar memotivasi } \\
\text { Anda untuk } \\
\text { berwirausaha }\end{array}$ & 0,666 & & & $\begin{array}{l}\text { Valid dan } \\
\text { Reliabel }\end{array}$ \\
\hline Faktor Lingkungan & & & & \\
\hline $\begin{array}{l}\text { 1. Budaya dan } \\
\text { kebiasaan } \\
\text { masyarakat sekitar }\end{array}$ & 0,778 & 0,781 & 0,852 & $\begin{array}{l}\text { Valid dan } \\
\text { Reliabel }\end{array}$ \\
\hline
\end{tabular}




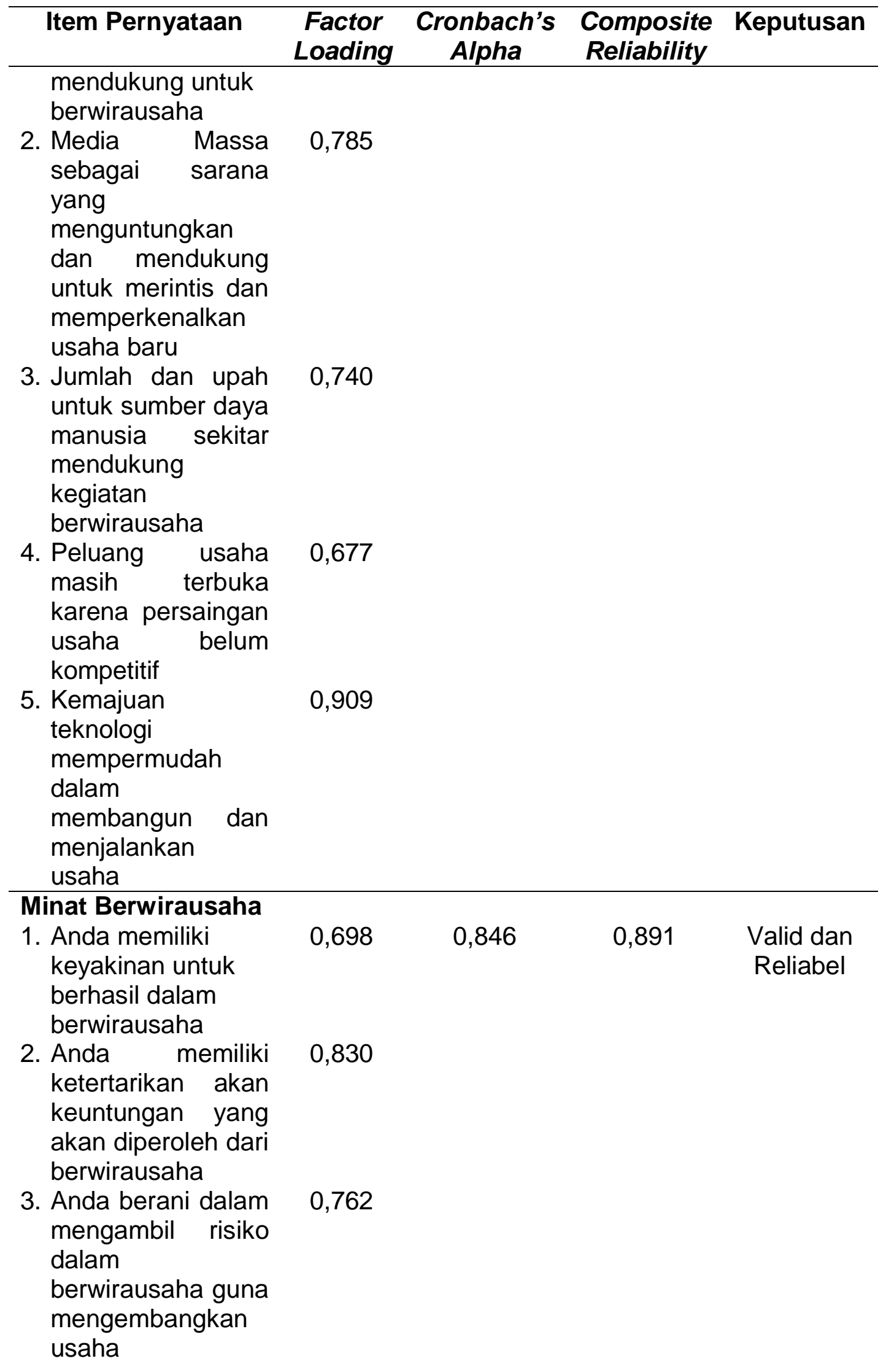




\begin{tabular}{|c|c|c|c|}
\hline Item Pernyataan & $\begin{array}{l}\text { Factor } \\
\text { Loading }\end{array}$ & $\begin{array}{c}\text { Cronbach's } \\
\text { Alpha }\end{array}$ & Keputusan \\
\hline $\begin{array}{l}\text { 4. Anda yakin dapat } \\
\text { memimpin dan } \\
\text { mengarahkan } \\
\text { orang lain sebagai } \\
\text { bawahan dalam } \\
\text { usaha Anda. }\end{array}$ & 0,704 & & \\
\hline $\begin{array}{l}\text { 5. Anda sudah } \\
\text { memiliki rencana } \\
\text { jangka menengah } \\
\text { dan panjang untuk } \\
\text { mengembangkan } \\
\text { usaha }\end{array}$ & 0,762 & & \\
\hline \multicolumn{4}{|c|}{$\begin{array}{r}\text { Sumber: Data Primer, Output SEM Warp PLS } 6.0 \\
\text { Tabel } 3 \text { Validitas Diskiriminan }\end{array}$} \\
\hline Variabel & $\begin{array}{c}\text { Motivasi } \\
\text { 3erwirausaha }\end{array}$ & Lingkungan & $\begin{array}{c}\text { Minat } \\
\text { erwirausaha }\end{array}$ \\
\hline $\begin{array}{c}\text { Motivasi } \\
\text { Berwirausaha }\end{array}$ & $(0,768)$ & 0,513 & 0,548 \\
\hline $\begin{array}{l}\text { Lingkungan } \\
\text { Minat } \\
\text { Berwirausaha }\end{array}$ & $\begin{array}{l}0,513 \\
0,548\end{array}$ & $\begin{array}{c}(0,736) \\
0,637\end{array}$ & $\begin{array}{c}0,637 \\
(\mathbf{0 , 7 9 0 )}\end{array}$ \\
\hline
\end{tabular}

Note: Square roots of average variances extracted (AVEs) shown on diagonal.

Sumber: Data Primer, Output SEM Warp PLS 6.0

Tabel 4 Goodness of Fit Models

\begin{tabular}{|c|c|c|c|}
\hline & Nilai & Kriteria [22] & Keputusan \\
\hline $\begin{array}{c}\text { Average Path Coefficient } \\
\text { (APC) }\end{array}$ & $\begin{array}{l}0,39 \\
7\end{array}$ & $P$ value $<=0,001$ & $\begin{array}{l}\text { Goodness of } \\
\text { Fit }\end{array}$ \\
\hline Average R-squared (ARS) & $\begin{array}{l}0,40 \\
6\end{array}$ & $P$ value $<=0,01$ & $\begin{array}{l}\text { Goodness of } \\
\text { Fit }\end{array}$ \\
\hline Average Block VIF (AVIF) & $\begin{array}{l}1,07 \\
6\end{array}$ & $\begin{array}{c}\text { Acceptable if }<=5, \text { ideally } \\
<=3,3\end{array}$ & $\begin{array}{l}\text { Goodness of } \\
\text { Fit }\end{array}$ \\
\hline $\begin{array}{c}\text { Average Full Collinearity VIF } \\
\text { (AFVIF) }\end{array}$ & $\begin{array}{l}1,60 \\
5\end{array}$ & $\begin{array}{c}\text { Acceptable if }<=5, \text { ideally } \\
<=3,3\end{array}$ & $\begin{array}{l}\text { Goodness of } \\
\text { Fit }\end{array}$ \\
\hline $\begin{array}{c}\text { Sympson's Paradox Ratio } \\
\text { (SPR) }\end{array}$ & $\begin{array}{l}1,00 \\
0\end{array}$ & $\begin{aligned} \text { Acceptable if }> & =0,7, \text { ideally } \\
& =1\end{aligned}$ & $\begin{array}{l}\text { Goodness of } \\
\text { Fit }\end{array}$ \\
\hline $\begin{array}{c}\text { R-squared Contribution } \\
\text { Ratio (RSCR) }\end{array}$ & $\begin{array}{l}1,00 \\
0\end{array}$ & $\begin{aligned} \text { Acceptable if }> & =0,9, \text { ideally } \\
& =1\end{aligned}$ & $\begin{array}{l}\text { Goodness of } \\
\text { Fit }\end{array}$ \\
\hline $\begin{array}{l}\text { Statistical Suppression } \\
\text { Ratio (SSR) }\end{array}$ & $\begin{array}{l}1,00 \\
0\end{array}$ & Acceptable if $>=0,7$ & $\begin{array}{l}\text { Goodness of } \\
\text { Fit }\end{array}$ \\
\hline
\end{tabular}

Sumber: Data Primer, Output SEM Warp PLS 6.0 
Tabel 2 menunjukkan bahwa lima item pernyataan motivasi berwirausaha, lima item pernyataan variabel lingkungan, dan lima item pernyataan minat berwirausaha dinyatakan valid. Sebab, nilai factor loading dari kelima belas item pernyataan yang digunakan dalam studi ini lebih tinggi dari dari 0,6. Selain itu, Tabel 2 juga memperlihatkan bahwa ketiga variabel dalam studi ini juga reliabel karena composite reliability dan crombach's alpha nilainya lebih dari 0,7. Berarti bahwa instrumen dari ketiga variabel ini menunjukkan konsistensi dan kehandalan untuk digunakan sebagai alat ukur.

Nilai akar AVE dari variabel motivasi berwirausaha, lingkungan, dan minat berwirausaha pada Tabel 3 nilainya lebih dari 0,6. Selain itu, nilainya juga lebih besar dibandingkan dengan korelasi antar variabel lainnya sehingga dinyatakan memenuhi syarat validitas diskriminan. Selanjutnya, studi ini juga menunjukkan kesesuaian model yang baik terbukti dari nilai ARS yaitu 0,406 dan APC yaitu 0,397 signifikan pada level $1 \%$. Selain itu, studi ini yang menggunakan variabel pemoderasi juga terbebas dari multikolinieritas sebab nilai AVIF dan AFVIF juga lebih kecil dari 3,3. Nilai SSR yang lebih dari 0,7 serta RSCR dan SPR juga memperlihatkan hasil ideal 1 menandakan kualitas dan kesesuaian model dengan data baik.

Total responden yang mengisi kuesioner secara lengkap dalam studi ini yaitu 100 responden. Karakteristik dari responden studi ini meliputi jenis kelamin, profesi, dan usia.

Tabel 5. Jenis Kelamin Responden

\begin{tabular}{ccc}
\hline Jenis Kelamin & Jumlah & Persentase (\%) \\
\hline Laki-laki & 45 & $45 \%$ \\
Permpuan & 55 & $55 \%$ \\
Total & 100 & $100 \%$ \\
\hline
\end{tabular}

Sumber: Data Diolah (2020)

Tabel 5. menunjukkan bahwa mayoritas dari responden studi ini yaitu perempuan sebanyak 55 orang. Sementara sisanya sebanyak 45 orang berjenis kelamin laki-laki.

Tabel 6. Profesi Responden

\begin{tabular}{|c|c|c|}
\hline Profesi & Jumlah & Persentase (\%) \\
\hline Pelajar/Mahasiswa & 15 & $15 \%$ \\
\hline Karyawan Swasta & 30 & $30 \%$ \\
\hline Petani & 25 & $25 \%$ \\
\hline PNS & 15 & $15 \%$ \\
\hline Lainnya & 15 & $15 \%$ \\
\hline Total & 100 & $100 \%$ \\
\hline
\end{tabular}

Sumber: Data Diolah (2020)

Sebagian besar responden studi ini berprofesi sebagai karyawan swasta sebesar $30 \%$ yang diperlihatkan pada Tabel 6 . Selanjutnya, sebesar $25 \%$ berprofesi sebagai petani. Terakhir masing-masing sebesar $15 \%$ untuk yang berprofesi pelajar/mahasiswa, PNS, dan lainnya. 
Tabel 7. Usia Responden

\begin{tabular}{cll}
\hline Rentang Usia & Jumlah & Persentase (\%) \\
\hline 17-24tahun & 35 & $35 \%$ \\
25-34 tahun & 30 & $30 \%$ \\
35-45 tahun & 20 & $20 \%$ \\
$>$ 45 tahun & 15 & $15 \%$ \\
\hline Total & $\mathbf{1 0 0}$ & $\mathbf{1 0 0 \%}$ \\
\hline
\end{tabular}

Sumber: Data Diolah (2020)

Tabel 7. Memperlihatkan bahwa usia dari responden studi ini didominasi oleh usia 17-24 tahun sebanyak 35 orang. Kedua diduduki oleh responden pada rentang usia 25-34 tahun sebesar 30 orang. Ketiga yaitu responden pada rentang usia 35-45 tahun dan terakhir responden yang memliki usia lebih dari 45 tahun.

Tahap kedua dari proses analisis SEM PLS dengan Warp PLS 6.0 yaitu uji hipotesis yang sering disebut dengan model struktural. Berikut ini hasil pengujian model struktural.

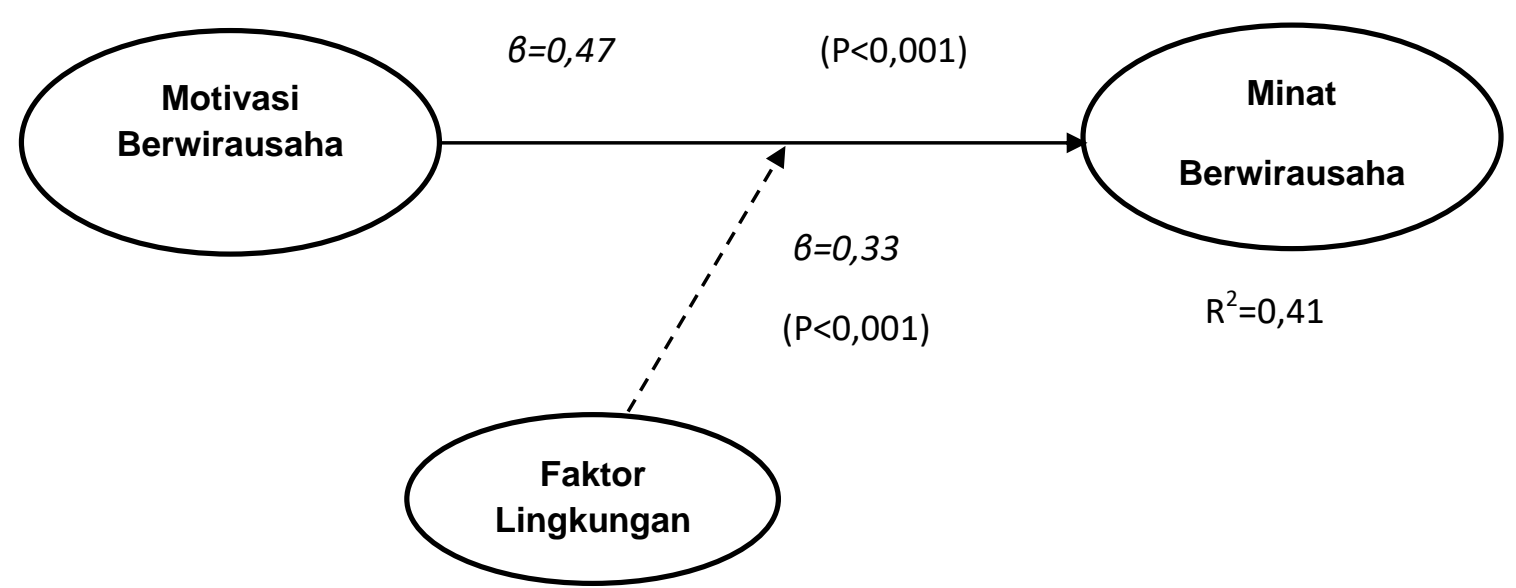

Gambar 1. Model Struktural

Tabel 8. Hasil Pengujian Hipotesis

\begin{tabular}{llcccc}
\hline Hipotesis & $\boldsymbol{\beta}$ & $\mathbf{R}^{2}$ & Effect Size & Keputusan \\
\hline H1 & $\begin{array}{l}\text { Motivasi berwirausaha } \\
\text { berpengaruh terhadap } \\
\text { minat berwirausaha }\end{array}$ & 0,47 & 0,41 & 0,26 & H1 diterima \\
H2 & $\begin{array}{l}\text { Faktor Lingkungan } \\
\text { memoderasi pengaruh } \\
\text { motivasi berwirausaha } \\
\text { terhadap minat } \\
\text { berwirausaha }\end{array}$ & 0,33 & & 0,15 & H2 diterima \\
\hline
\end{tabular}

Sumber: Data Primer, Output SEM Warp PLS 6.0

Hipotesis $1(\mathrm{H} 1)$ studi ini terdukung sebab nilai $\beta=0,47$ signifikan pada level 1 sesuai dengan yang tergambarkan pada Gambar 1 dan Tabel 8. Gambar 1 dalam hal ini juga memperlihatkan besarnya koefisien determinasi $\left(R^{2}\right)$ yaitu 0,41 artinya variabel motivasi berwirausaha bisa menjelaskan variansi dari variabel minat berwirausaha sebanyak $41 \%$. 
Selanjuntya, pada Tabel 8 terlihat bahwa effect size untuk pengaruh motivasi berwirausaha terhadap minat berwirausaha sebesar 0,26 (masuk kategori sedang). Nilai dari effect size tersebut menunjukkan bahwa motivasi berwirausaha memberikan peran cukup besar dari sudut pandang praktis untuk meningkatkan minat berwirausaha. Selanjutnya, hipotesis $2(\mathrm{H} 2)$ juga diterima karena nilai $\beta$ positif sebesar 0,33 dan signifikan. Dengan demikian, faktor lingkungan terbukti dapat memoderasi pengaruh motivasi berwirausaha terhadap minat berwirausaha. Nilai effect size yaitu 0,15 juga masuk kategori sedang, berarti secara praktis lingkungan dapat memperkuat pengaruh motivasi terhadap minat berwirausaha.

Hasil uji $\mathrm{H} 1$ membuktikan bahwa motivasi berwirusaha berpengaruh positif terhadap minat berwirausaha. Maksudnya bahwa tinggi maupun rendahnya motivasi berwirausaha yang dimiliki oleh individu juga selaras dengan tinggi rendahnya minat berwirausaha. Semakin tinggi motivasi seseorang untuk berwirausaha maka juga disertai dengan peningkatan minat berwirausaha. Temuan ini memperkuat studi Sektiyaningsih et al. (2020) dan Aqmala et al. (2020) bahwa motivasi berwirausaha menjadi faktor utama dalam meningkatkan minat berwirausaha. Hal ini juga sejalan dengan Kurniawan, Khafid, dan Pujiati (2016) yang menyatakan apabila motivasi berwirausaha itu menjadi bagian penting yang menentukan berhasil maupun tidak seseorang itu dalam berwirausaha termasuk dalam mengungkit besarnya minat berwirausaha dalam dirinya.

Hipotesis $2(\mathrm{H} 2)$ studi ini yaitu faktor lingkungan memoderasi pengaruh motivasi berwirausaha terhadap minat berwirausaha diterima. Artinya bahwa dengan adanya pengaruh lingkungan akan semakin memperkuat pengaruh motivasi terhadap minat berwirausaha. Temuan ini sesuai dengan pendapat dari Sumadi dan Sulistyawati (2017) bahwa minat berwirausaha itu tidak hanya dipengaruhi oleh faktor dari dalam diri seperti motivasi. Namun juga akan semakin kuat apabila juga dipengaruhi faktor lingkungan. Hal ini tidak terlepas dari individu yang berada di lingkungan yang penuh dengan ketidakpastian akibat perubahan teknologi. Dengan demikian, individu tidak terlepas dari pengaruh lingkungan tempatnya berada yang baik secara langsung maupun tidak akan memengaruhi kondisi psikologis serta sikap dan perilakunya.

\section{KESIMPULAN}

Secara statistik motivasi berwirausaha terbukti dapat meningkatkan minat berwirausaha sebesar $26 \%$. Selain itu, faktor lingkungan juga berhasil menjadi variabel pemoderasi yang mampu untuk memperkuat pengaruh motivasi berwirausaha terhadap minat berwirausaha.

\section{DAFTAR PUSTAKA}

Amalia, H.N. dan Hadi, S. (2016). Pengaruh Prestasi dan Lingkungan Terhadap Minat Berwirausaha Siswa Jurusan Pemasaran. 
Economic Education Analysis Journal, 5(3): 761-773.

Anggraeni, B. dan Harnanik. (2015). Pengaruh Pengetahuan Kewirausahaan dan Lingkungan Keluarga Terhadap Minat Berwirausaha Siswa Kelas XI SMK Islam Nusantara Comal Kabupaten Pemalang. Jurnal Pendidikan Ekonomi Dinamika Pendidikan, 10(1): 42-52.

Aqmala, D., Putra, F.I.F.S., dan Suseno, R.A. (2020). Faktor-faktor yang Membentuk Minat Berwirausaha Mahasiswa Program Studi Manajemen Universitas Dian Nuswantoro. Jurnal Ekonomi Manajemen Sumber Daya, 22(1): 60-70.

Badan Perencanaan Pembangunan Nasional (Bappenas). (2005). Visi dan Arah Pembangunan Jangka Panjang (PJP) Tahun 20052025.

Fadillah, M.N.R. dan Thamrin. (2019). The Influence of Entrepreneurial Motivation and Family Environment to the Public University Student's Toward Entrepreneurial Intention. Jurnal EcoGen, 2(1): 78-83.

Hair, F. J., Black, C. W., Babin, J. B., dan Anderson, E. R. (2014). Multivariate Data Analysis. London: Pearson Education Limited.

Hendrawan, J.S., dan Sirine, H. (2017). Pengaruh Sikap Mandiri, Motivasi, Pengetahuan Kewirausahaan Terhadap Minat Berwirausaha (Studi Kasus pada Mahasiswa FEB UKSW Konsentrasi Kewirausahaan). AJIE-Asian Journal of Innovation and Entrepreneurship, 2(3): 291314.

Kumalaningrum, M.P. (2012). Lingkungan Bisnis, Orientasi Kewirausahaan, Orientasi Pasar, dan Kinerja Usaha Mikro, Kecil, dan Menengah. Jurnal Riset Manajemen dan Bisnis, 7(1): 45-59.

Kurniawan, A., Khafid, M., dan Pujiati, A. (2016). Pengaruh Lingkungan Keluarga, Motivasi, dan Kepribadian terhadap Minat Wirausaha melalui Self Efficacy. Journal of Economic Education, 5(1): 100-109.

Lubis, P.K.D. (2018). Faktor-Faktor Yang Mempengaruhi Minat Mahasiswa Ekonomi. Jurnal Niagawan, halaman: 31-35.

Nainggolan, R. dan Harny, D. (2020). Pengaruh Pendidikan Entrepreneurship dan Lingkungan Sosial Terhadap Minat Berwirausaha (Studi di Universitas Ciputra). Jurnal Ekonomi Pendidikan dan Kewirausahaan, 8(2): 183-198.

Nurmayanti. (22 Oktober 2020). Rasio Kewirausahaan Inconesia Baru 3,47 Persen, Tertinggal dari Malaysia dan Thailand. URL www.lipitan6.com.

Sayektiningsih, I.S., Hardianawati, Aisyah, S. (2020). Analisis Pengaruh Pendidikan Kewirausahaan, Inovasi, dan Motivasi Berwirausaha Terhadap Minat Berwirausaha Pada Mahasiswa IBM ASMI Jakarta. JMBA-Jurnal Manajemen dan Bisnis, 6(2): 67-77.

Sumadi, A.R. dan Sulistyawati, E. (2017). Pengaruh Sikap, Motivasi, dan Lingkungan Terhadap Niat Berwirausaha. E-Jurnal Manajemen Unud, 6(2): 1007-1029. 
Suratno, Kohar, F., Rosmiati, dan Kurniawan, A. (2020). Pengaruh Pengetahuan Kewirausahaan, Media Sosial, Dan Motivasi Berwirausaha Terhadap Minat Berwirausaha Siswa/l Pada Smk Negeri 1 Kota Sungai Penuh. Jurnal IImu Manajemen Terapan, 1(5), 477-490. https://doi.org/10.31933/jimt.v1i5.212

Yusuf, M. dan Sutanti. (2020). Pengaruh Pendidikan Kewirausahaan dan Lingkungan Terhada Minat Berwirausaha di Kalangan Mahasiswa. Jurnal Muhammadiyah Manajemen Bisnis, 1(2): 77-84. 